\title{
The Differences of Wearing Shoes and Barefoot on Lower Limb Muscle Functions in Martial Arts Athletes of University
}

\author{
Tae-whan Kim ${ }^{1}$, Tae-hyun Lee², Tae-beom Seo ${ }^{3}$, Jl-hoon Cho4 ${ }^{4}$ Ki-hyuk Lee ${ }^{5}$, Jong-baek Lee ${ }^{*}$
}

${ }^{1}$ Korea Institute of Sport Science, Seoul, Korea

${ }^{2}$ Yong In University, Yongin, Korea

${ }^{3}$ Jeju National University, Jeju, Korea

${ }^{4}$ Shingyeong University, Hwaseong, Korea

${ }^{5}$ Korea National Sport University, Seoul, Korea

Received: May 3, 2018

Accepted: July 31, 2018

Published online: July 31, 2018

Keywords:
1RM
Balance
Barefoot Squat
EMG
Muscle power
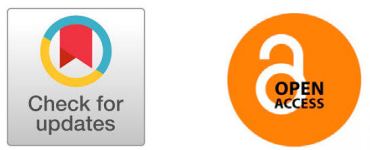

\begin{abstract}
OBJECTIVES The purpose of this study was to examine the differences of wearing shoes and barefoot on lower limb muscle functions in martial arts athletes of university.

METHODS Fourteen martial arts athletes participated in this study. Lower limb muscle functions (maximum strength, power, and electromyography) and balance were measured when wearing shoes (WS) and barefoot (BF). Measured data were analyzed using IBM SPSS Statistics ver. 23.0 (IBM Co., Armonk, NY, USA). Paired t-test was used for comparison between WS and BF.

RESULTS Maximum muscle strength (absolute and relative squat 1RM) and static balance (Standing on one leg with eyes close) were significantly higher in BF compared to WS. Although maximum muscle power and dynamic balance were higher in BF compared to WS, were non-significant. Muscle activities of rectus femoris and vastus lateralis were higher during WS than BF.

CONCLUSIONS The results of this study suggest that Application of barefoot training seems to be effective on expression of lower limb maximum muscle strength and static balance in martial arts athletes of university.
\end{abstract}

@ The Asian Society of Kinesiology and the Korean Academy of Kinesiology
서론

근력은 스포츠 선수들의 운동수행능력 향상에 많은 영 향을 미치는 요인으로 근력을 발달시키기 위해서 근력훈 련 초기에는 최대근력의 측정을 실시한다. 이는 개인의 근 력 수준을 평가하고 수준에 맞는 근력훈련을 실시하여 부

*Correspondence: Jong-baek Lee, Department of Sports Science, Korea Institute of Sport Science, 727 Hwarang-ro, Nowon-gu, Seoul, Korea.

E-mail: supertomcat100@hanmail.net
상의 위험을 낮추고 적합한 운동 강도와 운동량의 처방을 통해 훈련의 성과를 효율적으로 달성하기 위해서이다. 이 처럼 최대근력은 선수들의 근력상태에 대한 평가와 운동 처방뿐만이 아니라 최대근력수준의 훈련을 통하여 더 높 은 수준의 파워를 생성해낼 수 있는 밑바탕이 된다는 많은 연구들이 보고되고 있다[1-5]. 또한 최대근력수준의 높은 강도의 훈련은 골밀도의 증가에 효과적이며 $[6,7]$ 심혈관 능력의 실질적인 향상에도 높은 기여를 하는 것으로 보고 되고 있다[8].

한편 씨름을 비롯한 유도와 레슬링과 같은 무도 종목에 
서는 최대근력과 파워가 특히 중요한 체력요인으로 알려 져 있다[9]. 최대근력은 더 높은 수준의 파워를 생성해낼 수 있는 가장 밑바탕이 되는 체력요인으로 파워와 직접적 인 상관관계가 높다[1-5]. 최대근력을 향상시키는 방법으 로는 개인이 들어 올릴 수 있는 최대무게(maximum)의 저 항을 이용하는 방법과 최대하 무게(submaximum)를 실패 할 때까지 반복하는 방법, 그리고 최대하 무게를 최대스 피드로 반복하는 방법 등이 존재한다[10-12]. 최대근력을 효과적으로 향상시키기 위해서는 높은 수준의 운동단위 들을 활성화시켜야 하고 이를 위해서는 최대근력수준의 부하가 필요하다. 이러한 이유에서 최대무게수준에서의 훈련방법은 운동선수들의 최대근력향상을 위한 가장 효 과적인 훈련방법이라고 할 수 있다.

한편 스쿼트(squat)는 여러 스포츠종목에서 하지부위 최대근력 향상과 컨디셔닝 및 재활운동을 위해 보편적으 로 수행하고 있는 동작이다[13,14]. 그러나 스쿼트 동작 은 대표적인 다관절운동(multi-joint exercise)방법이기 때 문에 자세를 제어하기 어렵고, 동작 시 자세가 불안정하 면 그로 인해 허리와 무릎 등의 부상 발생 위험률이 높은 것으로 알려져 있다[15-17]. 이러한 동작의 위험성으로 인 하여 여러 선행연구에서는 스쿼트 동작 시 기본적인 자세 와 지침에 대하여 권고하고 있으며 자세의 안정성을 확보 하기 위한 방법을 제안하고 있다[18-20].

선행연구들은 스쿼트 동작에서 몸통과 발목 및 발바 닥부위가 스쿼트 동작의 자세안정성에 중요한 역할을 하 는 것으로 보고하고 있다[21]. 이에 따라 발목과 발바닥부 위의 안정성을 높이기 위한 방법으로 맨발인 조건에서의 스쿼트 동작에 관한 연구가 보고되었으며 맨발인 조건 은 발바닥에서부터의 구심성 감각(afferent neuron)을 향 상시키고 신체의 고유수용성감각(proprioception)을 향상 시켜 신체의 자세안정성을 개선하는 것으로 알려지고 있 다[22-24].

이에 따라 맨발과 신발의 착용유무 조건하에서 많은 연구가 보고되고 있으나 대부분의 연구는 달리기나 보행 및 밸런스와 관련된 연구가 주를 이루고 있으며[25-27] 근 력과 관련된 연구는 부족한 실정이다. Sato et al. [28]는 스 쿼트 동작 시 발목과 발바닥부위의 자세 안정성을 확인 하기 위하여 맨발인 조건과 신발을 신은 조건에서 스쿼 트 동작 시 각 관절 각도의 차이를 살펴보았으나 $1 \mathrm{RM}$ 의 60 80\%의 운동 강도에서 실시하였으며[28] 선수들의 최 대근력 발현 시 위험성을 이유로 최대근력과 관련된 연구
와 이해는 부족한 실정이다.

이에 본 연구는 맨발(barefoot)과 신발을 신은 조건 (shoes foot)하에서의 차이가 스쿼트 최대근력 및 파워 의 발현과 평형성 등 운동기능에 미치는 영향과 근전도 (electromyography)를 분석하여 최대근력과 파워가 중요 한 무도선수들의 훈련 프로그램 구성에 활용하는 것을 목 적으로 하였다.

\section{연구 방법}

\section{연구대상}

본 연구는 국내 Y대학에 재학 중인 남자 무도학과 선수 를 대상으로 하였다. 실험 실시 전 본 연구에 취지에 관하 여 설명을 한 후 동의서를 작성하도록 하였으며 동의에 응한 14 명의 선수들이 본 연구에 참가하였다. 연구대상자 들의 신체적 특성은 (Table 1)과 같다.

\section{측정변인 및 방법}

체력측정을 목적으로 태릉선수촌을 방문한 Y대학 무 도학과 선수를 대상으로 신발을 신었을 때와 맨발일 때 의 하지 근 기능을 비교하기 위해 하지 최대근력(Squat $1 \mathrm{RM})$, 최대파워 (Squat jump), 평형성(눈감고 외발서기, 동적평형성), 표면근전도(Electromyogram)를 측정하였 다. 신발은 같은 무게와 충격흡수기능을 가진 일반적인 러닝화로 통일하여 모든 측정자들의 신발 발바닥의 높이 와 신발의 충격흡수능력의 차이는 없었다. 신발의 조건 외 각각의 측정변인에 대한 측정방법은 다음과 같다.

최대근력(Squat 1RM) 최대근력의 차이를 객관적이고 정밀하게 평가하기 위하여 유압식형태의 단축성(Concentric contraction) 최대근력을 측정하는 전자식 최대근 력 측정기(ACE-2000, Ariel Dynamic INC, USA)를 활용하 여 $1 \mathrm{RM}(1 \mathrm{Repetition} \mathrm{Maximum)을} \mathrm{측정하였다[29].} \mathrm{피험자}$

\begin{tabular}{cc}
\multicolumn{2}{c}{ Table 1. Research participants (exploratory analysis) } \\
\hline Variables & Mean \pm SD \\
\hline Age(years) & $22.29 \pm 1.07$ \\
Height $(\mathrm{cm})$ & $178.36 \pm 6.88$ \\
Body weight $(\mathrm{kg})$ & $94.99 \pm 13.40$ \\
BMl & $29.96 \pm 4.66$ \\
Experience(years) & $8.57 \pm 2.44$ \\
\hline
\end{tabular}


들은 동일한 조건에서 각각 신발을 신었을 때와 맨발일 때로 나누어 3회씩 측정을 실시하였다. 측정동작은 바닥 과 허벅지가 평행이 되는 위치까지 내린 후 시작구호로 실시하였다.

1 회 $1 \mathrm{RM}$ 측정이 끝난 후 5 분의 휴식을 가지고 반복측정 을 실시하였으며, 다른 조건으로 넘어가는 시점에서 10 분 가량의 휴식시간을 가졌다. 이러한 휴식시간을 고려한 근 거는 Baker et al. [30]의 지속적인 근 수축을 하는 운동 이 후 5 분 내에 힘과 무기인산이 회복되었다는 연구결과를 근거로 하였다[30]. 한편 모든 변인은 사전 준비운동 이후 신발을 신은 상태에서 먼저 측정을 실시한 후 다음 측정 에 영향이 없도록 충분한 휴식시간을 가진 다음 맨발로 조건을 변경하여 측정을 계속 진행하였으며 가장 좋은 측 정값을 비교하였다.

최대파워(Squat jump) 최대파워를 측정하기 위해 스 쿼트 점프를 3회씩 실시하였다[29]. 점프는 신발을 신은 상태에서 양손은 허리를 붙잡고 무릎각도는 $90^{\circ}$ 까지 내 려간 후 바로 최대점프를 실시하였다. 측정값의 오차를 최소화하기 위하여 일정한 목표물을 제시하여 목표물에 닿을 만큼 최대한 점프를 유도하였다. 차렷 자세에서 최 고높이까지의 높이 차를 분석하여 비교하였다.

정적평형성 정적평형성의 차이를 비교분석하기 위하 여 눈감고 외발서기를 실시하였다[29]. 자신의 주된 발을 사용하여 측정하였으며 신발을 신은 상황에서 먼저 측정 한 다음 5 분간의 휴식을 취한 후에 다시 신발과 양말을 모 두 벗고 맨발인 상황에서 동일하게 실시하였다.

동적평형성 동적평형성의 차이를 비교분석하기 위하 여 동적평형성 측정 장비(Balance system SD Biodex, USA) 를 활용하여 전후, 좌우, 전체의 안정성을 측정하였다 [31]. 신발을 신은상태에서 동적평형성을 측정한 다음 맨 발인 상황에서 동일하게 실시하였으며 조건을 변경하는 측정 간에는 5 분간의 휴식을 취한 후 측정을 실시하였다. 동적평형성의 결과는 세 부위의 측정값을 표준점수를 구 하여 비교하였으며 표준점수가 낮을수록 안정성이 높은 결과를 의미한다.

표면근전도(Electromyography: EMG) 근육의 활동 정 도를 알아보기 위해 우측 하지의 넙다리곧은근(대퇴직
근, Rectus Femoris), 가쪽넓은근(외측광근, Vastus Lateralis), 넙다리두갈래근 (대퇴이두근, Biceps Femoris), 앞정 강근(전경골근, Tibialis Anterior), 큰볼기근(대둔근, Glutaus Maximus), 중간볼기근(중둔근, Gluteus Medius), 장딴 지근(비복근, Gastrocnemius), 가자미근(넙치근, Soleus)등 8 부위에 표면전극(Trigno wireless system, Delsys Inc., USA) 을 각각 부착하였다[32]. 근전도 자료의 표준화를 위하여 스쿼트의 앉는 자세는 어깨넓이의 범위에서 무릎의 각도 는 $90^{\circ}$ 에서 시작하도록 하여 측정하였으며, 무릎의 각도 가 $0^{\circ}$ (측정장비의 압력이 0 )이 되는 시점까지 기준으로 적 용하였다. 개인의 각 근육의 활동을 측정하기 위해 무선 근전도시스템(DTS Probe Transmitter, Noraxon USA, Inc, sample rates 1500 fixed, input impedance $>100 \mathrm{M} \Omega, \mathrm{CMRR}>$ $100 \mathrm{~dB}$, Input Range $+/-3.5 \mathrm{~V}$, center to center distance $=15 \mathrm{~mm}$ ) 을 사용하였다. 이때 동작의 이벤트 및 국면을 정하기 위 해 디지털 캠코더를 사용하여 수행하는 모습을 촬영하였 으며 근전도 자료와 동기화 하였다. 측정된 원 자료는 연 구대상자의 움직임과 실험 환경적인 요인으로 인한 노이 즈(noise)를 제거하기 위하여 FIR high pass filter 방법에 의 한 차단 주파수(cut-off frequency) $10 \mathrm{~Hz}$ 처리를 하였다. 이 후 full wave Rectification을 적용한 후 RMS $100 \mathrm{~ms}$ 으로 정 량화하였다. 근전도의 자료분석은 근육활동의 표준화를 위해 RVC(Reference Voluntary Contractions)형 태로 맨발인 조건에서의 근활성도를 표준으로 신발을 신은 조건에서 의 값을 나누어 백분율로 나타내어 활용하였다[33].

\section{자료처리}

측정된 자료는 SPSS WIN ver. 23.0 을 이용하여 분석하 였으며 각각의 측정변인들은 평균과 표준편차를 산출하 여 제시하였다. 변인들은 신발 착용 시와 맨발일 때를 비 교하기 위해 종속 t-검증(paired t-test)을 실시하여 평가하 였으며 통계적 유의 수준은 $\alpha=0.05$ 로 설정하였다.

\section{결과}

\section{최대근력 측정결과}

스쿼트 동작 시 최대근력(1RM)을 측정한 결과, 맨발의 경우가 신발 착용 시보다 절대근력 값과 $(\mathrm{p}=.044)$ 체중으 로 나눈 상대근력 값 $(\mathrm{p}=.05)$ 모두 유의하게 높은 것으로 나타났다. 자세한 결과는 (Table 2)와 같다. 


\begin{tabular}{lcccccc}
\multicolumn{6}{c}{ Table 2. Comparison of squat 1RM between WS and BF (Mean \pm SD) } \\
\hline Variables & Application & N & Mean \pm SD & t & p \\
\hline $\begin{array}{l}\text { Absolute } \\
\text { 1RM (kg) }\end{array}$ & WS & 14 & $194.86 \pm 20.91$ & & \\
& BF & 14 & $202.14 \pm 23.69$ & & \\
Relative & WS & 14 & $207.57 \pm 28.57$ & & \\
1RM (\%BW) & BF & 14 & $215.06 \pm 28.96$ & & \\
\hline${ }^{*} p<.05$, WS: wearing shoes, BF: bare foot & & &
\end{tabular}

\begin{tabular}{ccccccc}
\multicolumn{6}{c}{ Table 3. Comparison of squat jump between WS and BF $($ Mean \pm SD) } \\
\hline Variables & Application & $\mathrm{N}$ & Mean \pm SD & t & p \\
\hline $\begin{array}{c}\text { Absolute } \\
\text { squat jump } \\
\text { (cm) }\end{array}$ & WS & 14 & $43.79 \pm 7.19$ & & \\
\hline
\end{tabular}

WS: wearing shoes, BF: bare foot

\begin{tabular}{ccccccc}
\multicolumn{6}{c}{ Table 4. Comparison of SOE between WS and BF (Mean \pm SD) } \\
\hline Variables & Application & $\mathbf{N}$ & Mean \pm SD & t & p \\
\hline \multirow{2}{*}{ SOE (sec) } & WS & 14 & $22.55 \pm 14.84$ & & \\
& BF & 14 & $36.33 \pm 27.09$ & &
\end{tabular}

${ }^{*} p<.05$, SOE: Standing on one leg with eyes close, WS: wearing shoes, BF: bare foot

\begin{tabular}{|c|c|c|c|c|c|}
\hline Variables & Application & $N$ & Mean \pm SD & $\mathrm{t}$ & $p$ \\
\hline Anterior/ & WS & 14 & $7.52 \pm 5.21$ & & \\
\hline $\begin{array}{l}\text { Posterior } \\
\text { (index) }\end{array}$ & $\mathrm{BF}$ & 14 & $5.84 \pm 2.72$ & .949 & .361 \\
\hline Medial/ & WS & 14 & $3.85 \pm 2.05$ & & \\
\hline $\begin{array}{l}\text { Lateral } \\
\text { (index) }\end{array}$ & $\mathrm{BF}$ & 14 & $3.62 \pm 1.91$ & .380 & .710 \\
\hline $\begin{array}{l}\text { Overal } \\
\text { stability } \\
\text { (index) }\end{array}$ & WS & 14 & $\begin{array}{l}9.17 \pm 5.30 \\
7.45 \pm 3.57\end{array}$ & .934 & .369 \\
\hline
\end{tabular}

WS: wearing shoes, BF: bare foot

\section{최대파워 측정결과}

하지의 최대파워를 비교하기 위해 스쿼트 점프를 측정
한 결과, 맨발의 경우가 신발 착용 시보다 최대파워 값이 모두 높았으나 통계적으로 유의한 차이는 없었다. 자세한 결과는 (Table 3)과 같다.

\section{평형성 측정결과}

정적평형성(눈감고 외발서기)과 동적평형성을 측정 한 결과, 정적평형성은 맨발의 경우가 신발 착용 시보다 유의하게 높은 것으로 나타났다 $(\mathrm{p}=.026)$. 그러나 동적평 형성의 경우 전후, 좌우 전체 모두에서 맨발의 경우가 신 발 착용 시보다 안정성이 높았으나 통계적으로 유의한 차 이는 없었다. 자세한 결과는 (Table 4), (Table 5)와 같다.

\section{EMG 측정결과}

신발을 신었을 때와 맨발인 조건하에서 하지 8 부위에 대한 근활성도를 비교한 결과, 신발을 신었을 때가 맨발 인 조건 대비 넙다리곧은근과 가쪽넓은근이 각각 $18 \%$, $11 \%$ 더 활성화 되었다. 자세한 결과는 (Table 6)과 같다.

\section{논의}

본 연구는 신발 착용의 유무가 하지의 최대근력을 포 함한 운동수행능력(최대근력, 최대파워, 동적/정적 평형 성, 근육의 활성부위)에 어떠한 영향을 미치는지 비교 분 석하는데 목적이 있었다.

스쿼트 동작 시 최대근력을 측정한 결과 신발을 신고 있는 조건보다 맨발인 조건에서 최대근력이 유의하게 향 상된 것으로 나타났다. 맨발 스쿼트는 충격흡수기능이 없는 바닥과 쐐기 모양의 뒤꿈치, 미끄럼을 방지할 수 있 는 소재를 이용하여 Weight lifting의 힘의 증가를 목적으 로 하는 역도화의 이점에 착안하여 사용되기 시작한 방 법이다. 몸통과 발목 및 발바닥의 안정성은 최대근력수 행력을 높이는 데 중요한 역할을 하는 것으로 보고되었으 며[21] 맨발일 때의 운동감각은 신체적인 자세 안정성을 개선한다는 연구결과들이 보고되고 있다[22-24]. 이에 따 라 맨발인 상황은 신발 착용 시 보다 안정성을 향상시켜 최대근력의 발현을 증가시키는데 영향을 미치는 것으로 사료된다.

최대파워 평가를 위해 실시된 제자리 스쿼트 점프는 맨발인 조건이 신발 착용한 조건과 비교하여 평균적인 높 이는 높았지만 통계적으로는 유의한 차이를 나타내지 못 하였다. 이는 맨발인 조건과 신발을 착용한 조건하에서 
Table 6. Difference in lower limb muscle activity between WS and BF (unit: \%RVC)

\begin{tabular}{|c|c|c|c|c|c|c|c|c|}
\hline Subjects & $\mathrm{RF}$ & VL & TA & GM & GM' & $\mathrm{BF}^{\prime}$ & G & $S$ \\
\hline S1 & $91 \%$ & $101 \%$ & $69 \%$ & $99 \%$ & $88 \%$ & $114 \%$ & $80 \%$ & $107 \%$ \\
\hline S2 & $118 \%$ & $103 \%$ & $69 \%$ & $90 \%$ & $93 \%$ & $108 \%$ & $92 \%$ & $104 \%$ \\
\hline S3 & $158 \%$ & $112 \%$ & $140 \%$ & $118 \%$ & $120 \%$ & $88 \%$ & $125 \%$ & $113 \%$ \\
\hline S4 & $120 \%$ & $124 \%$ & $89 \%$ & $85 \%$ & $84 \%$ & $67 \%$ & $118 \%$ & $127 \%$ \\
\hline S5 & $123 \%$ & $113 \%$ & $99 \%$ & $107 \%$ & $107 \%$ & $104 \%$ & $101 \%$ & $98 \%$ \\
\hline S6 & $125 \%$ & $121 \%$ & $139 \%$ & $129 \%$ & $110 \%$ & $123 \%$ & $106 \%$ & $87 \%$ \\
\hline S7 & $105 \%$ & $105 \%$ & $96 \%$ & $91 \%$ & $99 \%$ & $111 \%$ & $68 \%$ & $86 \%$ \\
\hline S8 & $160 \%$ & $116 \%$ & $106 \%$ & $98 \%$ & $94 \%$ & $91 \%$ & $101 \%$ & $81 \%$ \\
\hline S9 & $94 \%$ & $94 \%$ & $67 \%$ & $72 \%$ & $76 \%$ & $71 \%$ & $69 \%$ & $87 \%$ \\
\hline S10 & $137 \%$ & $123 \%$ & $94 \%$ & $88 \%$ & $107 \%$ & $80 \%$ & $76 \%$ & $64 \%$ \\
\hline S11 & $104 \%$ & $107 \%$ & $91 \%$ & $86 \%$ & $87 \%$ & $87 \%$ & $86 \%$ & $83 \%$ \\
\hline $\mathrm{S} 12$ & $97 \%$ & $115 \%$ & $107 \%$ & $88 \%$ & $95 \%$ & $109 \%$ & $86 \%$ & $106 \%$ \\
\hline $\mathrm{S} 13$ & $107 \%$ & $112 \%$ & $104 \%$ & $117 \%$ & $121 \%$ & $113 \%$ & $129 \%$ & $122 \%$ \\
\hline S14 & $113 \%$ & $103 \%$ & $60 \%$ & $83 \%$ & $87 \%$ & $68 \%$ & $85 \%$ & $90 \%$ \\
\hline Mean & $118 \%$ & $111 \%$ & $95 \%$ & $97 \%$ & $98 \%$ & $95 \%$ & $94 \%$ & $97 \%$ \\
\hline SD & $21 \%$ & $9 \%$ & $24 \%$ & $16 \%$ & $14 \%$ & $19 \%$ & $20 \%$ & $17 \%$ \\
\hline
\end{tabular}

맨발인 조건이 능동적인 점프능력의 차이에는 별다른 영 향을 미치지 못하고 착지동작 시 충격흡수에만 신발의 착 용 유무가 영향을 미친다는 연구결과들과 일치하는 결과 이다[34-37]. 또한 스쿼트 점프는 최대 파워보다는 각 하 지근육들의 조화가 점프 높이에 더 큰 영향을 미치는 것 으로 보고되고 있으며[38] 이러한 연구결과와 본 연구에 서의 결과를 토대로 판단하였을 때 점프에 동원되는 각 근육들 간의 조화가 맨발인 조건에서 자세의 안정성이 향 상된 요인보다 제자리점프능력에 높은 영향을 미친 것으 로 판단되며, 이러한 이유에서 점프높이의 차이에 있어서 유의한 영향을 미치지 못한 것으로 사료된다[39].

한편 정적평형성(눈감고 외발서기)에서 신발 착용 시 보다 맨발인 조건에서 정적평형능력이 향상된 이유로는 첫째, 발목과 발바닥의 움직임에 대한 감각이 맨발인 조 건에서 보다 명확하게 구별되며[24] 이러한 발바닥에서 부터의 구심성감각의 향상은 신체의 고유수용성감각을 촉진시키고, 이러한 향상된 신체감각은 신체의 직립상태
유지를 위한 되먹임(Feedback)의 증가로 이어져 신체적 동요를 빠르게 지각시켜 자세안정성을 개선한다는 연구 결과와 일치한다고 할 수 있다[22-24].

둘째, 맨발인 상황은 신발을 착용했을 때 보다 발가락 을 모두 사용하여 지면을 내리 누를 수 있기 때문에 발바 닥부위의 기저면을 넓게 만들어서 안정성을 향상시킨다 [36]. 본 연구에서 맨발의 상황이 정적평형성을 향상시킨 요인으로 이러한 신체감각향상과 기계적인 안정성의 향 상으로 인한 것으로 사료된다. 하지만 본 연구에서는 동 적평형성에서는 맨발인 조건이 신발 착용한 조건과 비교 하여 평균적으로 높은 안정성을 나타냈지만 통계적으로 는 유의한 차이는 나타내지 못하였다. 이는 동적평형능력 은 움직이는 지면 발판을 통하여 선수의 균형능력을 평가 하였기에 정적평형능력 측정 시 맨발인 상황에서의 발가 락을 사용하여 기저면을 향상시켜 안정성을 높일 수 있었 던 특성[37]이 동적평형성에서는 상쇄되며 통계적인 유 의수준까지는 영향을 미치지 못한 것으로 보인다. 
마지막으로 신발을 착용한 것과 맨발인 조건의 스쿼트 동작에서 표면 근 전도를 측정한 결과 넙다리곧은군과 가 쪽넓은근의 평균 근 활성도는 신발을 착용한 상태에서 맨 발인 조건보다 높았다. 그 외에 넙다리두갈래근, 앞정강 근, 큰볼기근, 중간볼기근, 장딴지근, 가자미근은 신발을 착용한 조건이 맨발보다 평균적으로 다소 낮았다. Sato et al. [28]는 신발을 착용한 것과 맨발인 조건에서 스쿼트 동 작을 실시하여 관절의 각도를 비교한 결과, 신발을 착용 한 조건 $\left(88.32^{\circ}\right)$ 이 맨발인 조건 $\left(81.33^{\circ}\right)$ 보다 스쿼트 동작 의 무릎의 굴곡각도가 더 컸다고 하였다[28]. 한편, Caterisano et al. [40]는 스쿼트의 동작 깊이에 따른 주요 하체부 위의 근 활성도 연구에서 스쿼트 동작 깊이에 따라 대퇴 직근의 근 활성도의 차이를 보고하였으며[40] 맨발에서 상대적으로 작은 무릎각도는 스쿼트의 동작 시 앉은 자 세에서 깊이의 차이를 유발하며 따라서 상대적으로 대퇴 부 후면(Hamstrings)보다 대퇴부 앞면(Quadriceps)이 보다 활성화되어 하지 근육 각 부분의 활성도 차이를 유발하고 이러한 차이가 본 연구에서 맨발을 착용한 조건에서 대퇴 부 앞면의 활성화에 더 영향을 미친 요인으로 사료된다.

\section{결론}

다양한 형태의 하체근력훈련을 실시하는 무도선수들 을 대상으로 맨발인 조건과 신발을 착용한 조건에서 하지 근기능과 평형성을 비교 평가한 결과, 모든 변인에서 맨 발인 경우가 하지 근기능과 평형성이 향상된 것으로 나타 났다. 본 연구로 인해 최대근력향상 훈련을 위한 $1 \mathrm{RM}$ 훈 련 시 맨발인 조건하에서의 트레이닝은 선수들에게 보다 높은 부하자극을 주는데 이용가능하며, 선수들의 무릎손 상 등 하지 손상과 관련하여 재활초기 관절의 안정성 향 상을 위한 지침으로 활용될 수 있을 것으로 보인다.

한편 본 연구는 단발적인 비교실험이기 때문에 맨발을 이용한 트레이닝의 효과를 검증하기 위해서는 일정한 트 레이닝 기간을 거쳐 맨발 트레이닝이 신발을 착용한 트레 이닝보다 최대근력을 포함한 근기능과 평형성을 향상을 시킬 수 있는지에 대해 검증할 수 있는 후속연구가 필요 할 것으로 사료된다.

\section{Conflicts of Interest}

The authors declare no conflict of interest.

\section{References}

1. McBride JM, Triplett-McBride T, Davie A, Newton RU. A Comparison of Strength and Power Characteristics Between Power Lifters, Olympic Lifters, and Sprinters. J Strength Cond Res. 1999; 13(1):58-66.

2. Duchateau J, Hainaut K. Mechanisms of muscle and motor unit adaptation to explosive power training. Strength and power in sport, 2003, p 315.

3. Stone MH, O'bryant HS, Mccoy L, Coglianese R, Lehmkuhl M, Schilling B. Power and maximum strength relationships during performance of dynamic and static weighted jumps. J Strength Cond Res. 2003; 17(1):140-147.

4. Baker DG, Newton RU. Comparison of lower body strength, power, acceleration, speed, agility, and sprint momentum to describe and compare playing rank among professional rugby league players. J Strength Cond Res. 2008; 22(1):153-158.

5. Prue $\mathrm{P}, \mathrm{McGuigan} \mathrm{MR}$, Newton RU. Influence of strength on magnitude and mechanisms of adaptation to power training. Med Sci Sports Exerc. 2010; 42(8):1566-1581.

6. Ryan AS, Ivey FM, Hurlbut DE, et al. Regional bone mineral density after resistive training in young and older men and women. Scand J Med Sci Sports. 2004; 14(1):16-23.

7. Almstedt HC, Canepa JA, Ramirez DA, Shoepe TC. Changes in bone mineral density in response to 24 weeks of resistance training in college-age men and women. J Strength Cond Res. 2011; 25(4):1098-1103.

8. Alcaraz PE, Sánchez-Lorente J, Blazevich AJ. Physical performance and cardiovascular responses to an acute bout of heavy resistance circuit training versus traditional strength training. J Strength Cond Res. 2008; 22(3):667-671.

9. Cho HC, Kim YH, Kim JP et al. The Correlation of BMD, Isokinetic Muscle Strength and anaerobic power on Body Parts in Combat Sports Athlete. J Korean Alliance Martial Arts. 2011; 13(3):175-186.

10. Zatsiorsky VM, Kraemer WJ. Science and practice 
of strength training. Illinois, USA. Human Kinetics. 2006, p 81.

11. Schoenfeld BJ, Peterson MD, Ogborn D, Contreras B, Sonmez GT. Effects of low-vs. high-load resistance training on muscle strength and hypertrophy in welltrained men. J Strength Cond Res. 2015; 29(10):29542963.

12. Mangine GT, Hoffman JR, Wang R, et al. Resistance training intensity and volume affect changes in rate of force development in resistance-trained men. Eur J Appl Physiol. 2016; 116(11-12):2367-2374.

13. Panariello RA, Backus SI, Parker JW. The effect of the squat exercise on anterior-posterior knee translation in professional football players. Am J Sports Med. 1994; 22(6):768-773.

14. Thein JM, Brody LT. Aquatic-based rehabilitation and training for the elite athlete. J Orthop Sports Phys Ther. 1998; 27(1):32-41.

15. Williams JG. Biomechanical factors in spinal injuries. Br J Sports Med. 1980; 14:14-17.

16. O'Shea P. The paralled squat. J Strength Cond Res. $1985 ; 7: 4-6$.

17. Fry AC. Coaching considerations for the barbell squat-Part1, J Strength Cond Res. 1993; 15(2):556569.

18. Hart DL, Stobbe TJ, Jaraied M. Effect of lumbar posture on lifting. Spine. 1987; 12(2):138-145.

19. Granhed H, Jonson R, Hansson T. The loads on the lumbar spine during extreme weight lifting. Spine. 1987; 12(2):146-149.

20. Granata KP, England SA. Stability of dynamic trunk movement. Spine. 2006; 31(10): E271.

21. Kavounoudias A, Roll R, Roll JP. Foot sole and ankle muscle inputs contribute jointly to human erect posture regulation. J Physiol. 2001; 532(3):869-878.

22. Watanabe I, Okubo J. The role of the plantar mechanoreceptor in equilibrium control. Ann N Y Acad Sci. $1981 ; 374(1): 855-864$.

23. Maki BE, Perry SD, Norrie RG, McIlroy WE. Effect of facilitation of sensation from plantar foot-surface boundaries on postural stabilization in young and older adults. J Gerontol A Biol Sci Med Sci. 1999; 54(6):M281-M287.

24. Waddington G, Adams R. Football boot insoles and sensitivity to extent of ankle inversion movement. $\mathrm{Br}$ J Sports Med. 2003; 37(2):170-175.

25. Squadrone R, Gallozzi C. Biomechanical and physiological comparison of barefoot and two shod conditions in experienced barefoot runners. J Sports Med Phys Fitness. 2009; 49(1):6-13.

26. Vormittag K, Calonje R, Briner WW. Foot and ankle injuries in the barefoot sports. Curr Sports Med Rep. 2009; 8(5):262-266.

27. Sinclair J. Effects of barefoot and barefoot inspired footwear on knee and ankle loading during running. Clin Biomech. 2014; 29(4):395-399.

28. Sato K, Fortenbaugh D, Hydock D, Heise G. Comparison of back squat kinematics between barefoot and shoe conditions. Int J Sports Sci Coach. 2013; 8(3): 571-578.

29. Chung JW, Kim KJ, Kim HJ. Effects of physique and fitness on performance of each event in elite alpine skier. Exerc Sci. 2011; 20(1):71-80.

30. Baker AJ, Kostov KG, Miller RG, Weiner, MW. Slow force recovery after long-duration exercise: metabolic and activation factors in muscle fatigue. J Appl Physiol. 1993; 74(5):2294-2300.

31. Arnold BL, Schmitz RJ. Examination of balance measures produced by the biodex stability system. J Athl Train. 1998; 33(4):323-327.

32. Choi NY, Jang HS, Shin YA. The Effect on Muscle Activation in Trunk and Low-limbs during Squat Exercise on Various Instability Surface. Koran J Phys Educ. 2015; 54(1):505-514.

33. Kim CH, Kim MY, Moon JH, Lim BO. Effects of Hoehn-Yahr Scale on the Activation of Lower Extremity Muscles during Walking with Parkinson's Patients. Korean J Sports Biomech. 2014; 24(3):287-293.

34. Dufek JS, Bates BT, Davis HP, Malone LA. Dynamic performance assessment of selected sport shoes on impact forces. Med Sci Sports Exerc. 1991; 23(9): 1062-1067. 
35. Park SN. Kinetic Differences in Ground Reaction Force According to Different Shoe and Insole Types During Keun Pat Chim Ddwim Che. J Korean Dance Sci. 2005; 11:25-36.

36. Yi KO, Kwon BY. Differences in Vertical Ground Reaction Force According to the Use of Insoles for Vertical Jumps in Rhythmic Gymnastics. J Korean Assoc Phys Educ Sport Girls Women. 2005; 19(4):85-92.

37. Yan AF, Sinclair PJ, Hiller C, Wegener C, Smith RM. Impact attenuation during weight bearing activities in barefoot vs. shod conditions: a systematic review. Gait posture. 2013 ; 38(2):175-186.
38. Umberger BR. Mechanics of the Vertical Jump and Two-Joint Muscles: Implications for Training. Strength Cond Res J. 1998; 20(5):70-74.

39. Samozino P, Morin JB, Hintzy F, Belli A. A simple method for measuring force, velocity and power output during squat jump. J Biomech. 2008; 41(14): 2940-2945.

40. Caterisano A, Moss RE, Pellinger TK, Woodruff K, Lewis VC, Booth W, Khadra T. The effect of back squat depth on the EMG activity of 4 superficial hip and thigh muscles. J Strength Cond Res. 2002; 16(3):428-432. 